University of Montana

ScholarWorks at University of Montana

$10-2012$

\title{
Neo-Allopatry and Rapid Reproductive Isolation
}

Daniel Montesinos

Gilberto Santiago

Ragan M. Callaway

University of Montana - Missoula, Ray.Callaway@mso.umt.edu

Follow this and additional works at: https://scholarworks.umt.edu/biosci_pubs

Part of the Biology Commons

Let us know how access to this document benefits you.

\section{Recommended Citation}

Montesinos, Daniel; Santiago, Gilberto; and Callaway, Ragan M., "Neo-Allopatry and Rapid Reproductive Isolation" (2012). Biological Sciences Faculty Publications. 207.

https://scholarworks.umt.edu/biosci_pubs/207

This Article is brought to you for free and open access by the Biological Sciences at ScholarWorks at University of Montana. It has been accepted for inclusion in Biological Sciences Faculty Publications by an authorized administrator of ScholarWorks at University of Montana. For more information, please contact

scholarworks@mso.umt.edu. 


\title{
Neo-Allopatry and Rapid Reproductive Isolation
}

\author{
Daniel Montesinos, ${ }^{1,2,3 *}$ Gilberto Santiago, ${ }^{1,4}$ and Ragan M. Callaway ${ }^{1}$ \\ 1. Division of Biological Sciences, University of Montana, Missoula, Montana 59812; 2. Centro de Investigaciones sobre Desertificación \\ (Consejo Superior de Investigaciones Científicas-Universitat de València-Generalitat Valenciana), Apartado Oficial 46113, Moncada, \\ Spain; 3. Center for Functional Ecology, Universidade de Coimbra, Apartado 3046, 3001-401 Coimbra, Portugal; 4. Universidad de \\ Puerto Rico, P.O. Box 9000, Mayagüez 00681, Puerto Rico
}

Submitted December 7, 2011; Accepted June 4, 2012; Electronically published August 3, 2012

Dryad data: http://dx.doi.org/10.5061/dryad.97g9b.

Aвstract: Over the past 3 centuries, many species have been dispersed beyond their natural geographic limits by humans, but to our knowledge, reproductive isolation has not been demonstrated for such neo-allopatric species. We grew seeds from three species of Centaurea (Centaurea solstitialis, Centaurea calcitrapa, and Centaurea sulphurea) that are native to Spain and have been introduced into California, and we tested to what extent seed production was affected by pollen source. Compared with within-population crosses, seed production decreased by $52 \%$ and $44 \%$, respectively, when C. solstitialis and C. sulphurea from California were pollinated with conspecific pollen from native populations in Spain. This implies rapid evolution of reproductive isolation between populations in their native and nonnative ranges. Whether reproductive isolation has evolved following the introduction of other species is unknown, but additional cases are likely, considering the large number of neoallopatric species.

Keywords: reproductive isolation, invasive weeds, hybridization, Centaurea solstitialis, Centaurea calcitrapa, Centaurea sulphurea.

\section{Introduction}

A central model for speciation is that when populations are geographically isolated, gene flow between them ceases and genetic drift and adaptation to different environments lead to genetic divergence and reproductive isolation (Mayr 1942). Reproductive isolation among existing populations has been demonstrated for plant and animal species (MacNair and Christie 1983; Funk et al. 2006; Lowry et al. 2008), and experimental laboratory studies have successfully produced reproductive isolation after roughly hundreds of generations (Rice and Hostert 1993). Speciation has been reported to occur via hybridization in as few as 300 years for species in the genus Senecio (James and Abbott 2005); however, evidence for rapid reproduc-

\footnotetext{
* Corresponding author; e-mail: danimontesinos@gmail.com.
}

Am. Nat. 2012. Vol. 180, pp. 000-000. (c) 2012 by The University of Chicago. 0003-0147/2012/18004-53500\$15.00. All rights reserved. DOI: $10.1086 / 667585$ tive isolation in nature without hybridization is rare (Schluter 2000, 2001; Coyne and Orr 2004; Hendry 2004; Hendry et al. 2007). Humans are eliminating dispersal barriers and dramatically expanding the global distributions of many species (Pimentel et al. 2005; Hulme 2007). The result is that some recently established populations are geographically isolated from their source populations, and we refer to this as neo-allopatry. Cross-continental introductions in particular have rapidly isolated populations of many species, and there is circumstantial evidence for divergent selection between native and nonnative ranges for ecological traits such as growth, herbivore defense, and competitive ability (Callaway and Ridenour 2004; Maron et al. 2004; Ridenour et al. 2008; Whitney and Gabler 2008; Hierro et al. 2009). Theory predicts that divergent selection of ecological traits can drive reproductive isolation and, eventually, speciation (Funk et al. 2006). Thus, exotic invasions provide exceptionally good natural experiments in which to look for the development of reproductive barriers, but to date there is no evidence for any form of reproductive isolation for neo-allopatric species.

Centaurea solstitialis, Centaurea calcitrapa, and Centaurea sulphurea are closely related annual plants within the Jacea group of the Centaurea phylogeny (Garcia-Jacas et al. 2006) and have overlapping distributions in their native range of Spain and also in California, where they have been introduced. Two of these neo-allopatric species, $C$. solstitialis and C. calcitrapa, occur over broad native (Southern Europe) and nonnative ranges (Americas, Australia; Maddox et al. 1985; Gerlach and Rice 2003), whereas C. sulphurea has a highly restricted native range in Spain and Morocco, and only a few populations have been found in California. Centaurea solstitialis has become an aggressive invader in California, where it was introduced by or before 1824 (Maddox et al. 1985). Centaurea solstitialis was first introduced into Chile from Spain and then secondarily introduced into California via contaminated al- 
falfa seeds from Chile (Gerlach 1997; Hierro et al. 2009). Centaurea calcitrapa and C. sulphurea are thought to have been introduced to California by 1896 and 1923, respectively (Robbins 1940; Barbe 1989; Pitcairn et al. 2002; Muth and Pigliucci 2006). These latter two species have naturalized without becoming noxious invaders (Gerlach and Rice 2003). All three species are diploid, with no polyploidy yet reported (Heiser and Whitaker 1948; Powell et al. 1974; Sun and Ritland 1998). Centaurea solstitialis is self-incompatible (Sun and Ritland 1998), while the other two species are self-compatible (Forney 1997; Gerlach and Rice 2003). Thus, these species provide a good comparative system to test for reproductive isolation between species and between native and nonnative ranges.

\section{Methods}

In the summer of 2009, we collected seeds from each of fifteen different individuals from each of 45 different populations across the distributional ranges of the three species in Spain and California (see table A1, available in Dryad; http://dx.doi.org/10.5061/dryad.97g9b). We sampled eight Centaurea solstitialis populations from Spain and 11 populations from California, 10 Centaurea calcitrapa populations from Spain and nine from California, and four Centaurea sulphurea populations from Spain and three from California. Seeds from each mother plant were grown in a greenhouse ( $n=675$ plants). Seeds were germinated in pots $(2.2 \mathrm{~L})$ with a $50: 50 \mathrm{mix}$ of 20-30-grit sand and local soil from Missoula, Montana. Plants were watered every 1-2 days and fertilized biweekly with $100 \mathrm{~mL}$ of 1.16 g L $^{-1}$ Scotts Miracle-Gro (15:30:15 + micronutrients). The greenhouse was sealed with fine mesh $(0.5 \mathrm{~mm})$ to exclude pollinators.

At reproductive maturity, different pollen donors were randomly chosen for each treatment, and for each individual plant, each inflorescence (capitula) was manually pollinated with a different pollen donor. Manual pollinations were performed using a brush, and the seeds produced by those inflorescences were counted. Pollination treatments were organized in a factorial design in which each population had several replicates of intra- and interpopulation, intra- and intercontinental, and intra- and interspecific crosses. A total of 848 intracontinental (including intra- and interpopulation crosses), 46 intercontinental, and 55 interspecific pollinations were made for C. solstitialis; 1,277 intracontinental and 58 intercontinental pollinations for C. calcitrapa; and 269 intracontinental and 51 intercontinental pollinations for C. sulphurea. Emasculation of composite capitula with numerous inflorescences and with different flowering times was beyond our reach, but this is not a problem for the interpretation of results of the self-incompatible C. solstitialis (Sun and
Ritland 1998). However, self-compatibility might mask the occurrence of true reproductive barriers for the two noninvasive species. Data from manual pollinations were analyzed separately for each species and continent, using $\mathrm{R}$ 2.14.1 (Crawley 2007; R Development Core Team 2010). We used generalized linear mixed effects models (glmmPQL; Venables and Ripley 2002; Zuur et al. 2009) with Poisson error distribution to test for differences in total number of seeds per capitula between pollination treatments. Individual mother plant nested within population was used as a random factor. To test for differences in morphological characteristics, we used SPSS 19 (Norusis 2002) to perform nested GLMs for each species, with inflorescence number, seed size, seed germination, and plant size as dependent variables and individual plants nested within population as a random effect.

\section{Results}

Centaurea solstitialis grown from seed from Spanish populations produced a similar number of seeds per flower when treated with pollen from plants from California and plants from Spain $(t=-0.91$, df $=1,436, P=.364$; fig. 1). However, C. solstitialis from Californian populations produced $52 \%$ fewer seeds with pollen from Spanish plants than with pollen from Californian plants $(t=-2.69$, $\mathrm{df}=1,770, P=.007)$. Between- and within-population pollinations within each continent did not differ in seed set for Spain $(t=-0.73, \mathrm{df}=1,436, P=.466)$, but Californian plants produced $25 \%$ fewer seeds per inflorescence when pollinated by plants from a different Californian population than by plants from the same population ( $t=-2.39, \mathrm{df}=1,770, P=.017)$. Centaurea sulphurea from Spanish populations experienced a $20 \%$ reduction in seed set when treated with pollen from Californian plants $(t=-2.39, \mathrm{df}=1,241, P=.018)$. Centaurea sulphurea from Californian populations experienced an even larger reduction, producing $44 \%$ fewer seeds when pollinated with pollen from Spanish plants than when pollinated with pollen from Californian plants $(t=-3.75$, $\mathrm{df}=1,218, P<.001)$. Seed production of Centaurea calcitrapa showed no differences between pollen donors or recipients from different ranges (Spain: $t=-0.77$, $\mathrm{df}=1,873, \quad P=.441 ; \quad$ California: $\quad t=-0.31, \quad \mathrm{df}=$ $1,647, P=.749$ ).

We also measured significant differences in morphological traits between plants collected on the different continents, which is consistent with ecological divergence. Centaurea solstitialis plants grown from seed from Californian populations produced 15\% fewer inflorescences $(F=3.41, \mathrm{df}=2,18, P=.055)$ and $50 \%$ larger seeds $(F=67.5, \mathrm{df}=1,12, P<.001)$, grew $5 \%$ taller $(F=$ 17.93, $\mathrm{df}=2,18, \quad P<.001)$, had $21 \%$ longer spines 


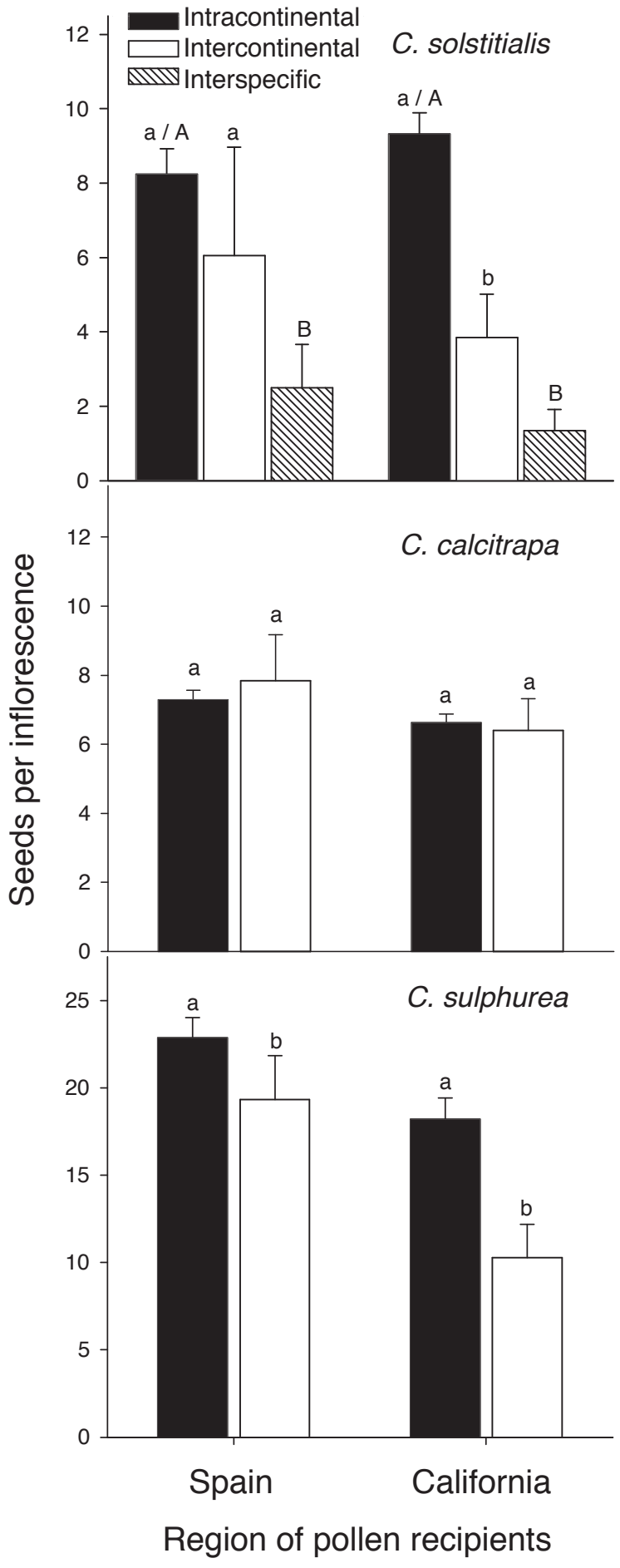

Figure 1: Number of seeds (mean \pm SE) per inflorescence (capitulum) for Spanish and Californian Centaurea pollinated with pollen from plants from the same continent (intracontinental), from a dif-
$(F=17.33, \mathrm{df}=2,18, P<.001)$, and produced seeds with $38 \%$ higher germination rates $(F=12.20$, df $=1,19$, $P<.002)$ than plants grown from seeds from Spanish populations. Centaurea calcitrapa from California also produced a greater number of inflorescences $(F=9.91$, $\mathrm{df}=2,18, P=.013)$ and grew larger $(F=4.45$, df $=$ $2,18, P=.027)$ than Spanish conspecifics. Centaurea sulphurea from California germinated at higher rates $(F=$ 20.63, df $=1,5, P=.006)$ than its Spanish conspecifics.

A strict interpretation of the biological species concept is that reproductive isolation between different species needs to be complete (100\% isolation); however, interspecific crosses for C. calcitrapa or C. sulphurea produced viable seeds for plants from Spanish populations (65\% reduction in seed set; $t=-3.10$, df $=1,469, P=.002)$ and for plants from California ( $88 \%$ reduction; $t=-3.64$, df $=$ $1,827, P<.001)$, with an average reduction in fertility of $77 \%$. There were no differences in seed set between the latter two species as pollen donors $(t=-1.47$, $\mathrm{df}=$ $1,33, P=.150)$.

\section{Discussion}

Plant speciation can occur within centuries via hybridization (James and Abbott 2005); however, in the absence of hybridization, speciation is generally thought to take far longer (Coyne and Orr 2004; Vellend et al. 2007). We found that seed production by the nonhybrid Centaurea solstitialis and Centaurea sulphurea was reduced by $52 \%$ and $44 \%$, respectively, when North American plants were pollinated by conspecifics from Europe, when compared with those pollinated by conspecifics from North America. This implies that a degree of reproductive isolation has developed rapidly - within $<200$ years-between populations in their native and nonnative ranges. Interspecific crosses produced $77 \%$ fewer seeds per inflorescence than intraspecific $C$. solstitialis crosses. If we estimate that interspecific crosses represent an upper limit of reproductive isolation among these species, the reproductive isolation we detected between Californian and Spanish populations of C. solstitialis was $68 \%$ of that limit.

To our knowledge, our results provide the first evidence for rapid reproductive isolation arising between populations in the native and nonnative ranges of exotic species. Future research should describe the mechanisms respon-

ferent continent (intercontinental), or from different species (interspecific). Different letters indicate significant differences between treatments within each region. Lowercase letters indicate differences for intraspecific treatments. Uppercase letters indicate differences for interspecific treatments. Interspecific results are shown for the only selfincompatible species, Centaurea solstitialis. 
sible for the levels of reproductive isolation detected between Centaurea populations (e.g., Ramsey et al. 2003; Lowry et al. 2008). However, in the study species, flower morphology and phenology do not differ among regions (D. Montesinos, personal observation), and thus prepollination reproductive barriers are unlikely to be important. Potential mechanisms of postpollination reproductive isolation include pleiotropy, genetic hitchhiking, chromosomal inversions, Bateson-Dobzhansky-Muller interactions, genetic bottlenecks that occurred during the process of geographic isolation, and changes in ploidy (Barton 2010; Rieseberg and Blackman 2010; Schemske 2010; Wolf et al. 2010). The three Centaurea species we studied are diploid on both continents (Heiser and Whitaker 1948; Powell et al. 1974; Sun and Ritland 1998); thus, polyploid speciation is unlikely. We did not sample all populations in the native range, so we cannot exclude the possibility that reproductive isolation occurred among populations that we failed to collect in the native range and that these preisolated populations are now common in California. However, our extensive interpopulation pollinations within the native range found no evidence for reproductive isolation. Also, even if reproductive isolation has occurred within populations in the native range, our results would suggest that new allopatric distributions can create the spread of reproductive barriers that are far less common in the native range.

The noninvasive species Centaurea calcitrapa and C. sulphurea are self-compatible. Highly self-compatible plants are not likely to show a difference between pollination treatments, since self-pollination should make up for any pollen scarcity. However, individuals of the self-compatible C. sulphurea showed a reduction in seed set when pollinated with pollen from a different region. This suggests that incompatible pollen from a different region germinated in the style, thus competing with local pollen and resulting in a reduced seed set for intercontinental crosses. The fact that C. sulphurea demonstrated bidirectional reproductive isolation suggests that this may occur in the future for $C$. solstitialis or that some degree of reproductive isolation between Spain and California may already be present for Spanish individuals and that we were unable to detect it as a result of Type II error (a false negative).

For C. solstitialis, the only self-incompatible species we tested, the reported degree of isolation appears to have occurred in fewer than 200 generations. Other studies in $\rightarrow$ dicate that local adaptation in seed and seedling size, seed morphology, and seed dormancy has occurred since the introduction of C. solstitialis into the United States (Widmer et al. 2007; Hierro et al. 2009). Such local adaptation and reproductive isolation might contribute to invasiveness (e.g., by fixing advantageous adaptations in the more adapted populations of the nonnative range), but since the noninvasive C. sulphurea also shows evidence of intercontinental reproductive isolation, isolation per se may be unlikely to explain invasiveness.

Our results are unlikely to be unique, considering the rate at which evidence for divergent selection for ecological traits between native and nonnative ranges is being found (Callaway and Ridenour 2004; Maron et al. 2004; Ridenour et al. 2008; Whitney and Gabler 2008; Hierro et al. 2009) and the very large numbers of species that have become neo-allopatric in the past few centuries, with many more likely to occur in the near future. Exploring reproductive isolation in neo-allopatric organisms and the mechanisms by which they achieve reproductive isolation may teach us much about speciation and the rate at which it can occur.

\section{Acknowledgments}

We are very thankful to D. Hooper, A. Krutulis, S. Paula, M. Zorrilla, and the crew at Callaway lab for their hard work. Thanks to L. Fishman and D. Schemske for their feedback. D.M. was funded by the Spanish Micinn (20080662) and by the Portuguese Fundação para a Ciência e a Tecnologia (SFRH/BPD/72595/2010). R.M.C. was funded by National Science Foundation DEB 0614406. G.S. was supported by the Introductory Multicultural Summer Undergraduate Research Experience at the University of Montana.

\section{Literature Cited}

Barbe, G. D. 1989. Noxious weeds of California. 1. Distribution maps: Centaurea sulphurea. California Department of Food and Agriculture, Sacramento.

Barton, N. H. 2010. What role does natural selection play in speciation? Philosophical Transactions of the Royal Society B: Biological Sciences 365:1825-1840.

Callaway, R. M., and W. M. Ridenour. 2004. Novel weapons: invasive success and the evolution of increased competitive ability. Frontiers in Ecology and the Environment 2:436-443.

Coyne, J. A., and H. A. Orr. 2004. Speciation. Sinauer, Sunderland, MA.

Crawley, M. J. 2007. The R book. Wiley, West Sussex.

Forney, T. 1997. Plant pest risk assessment for purple starthistle, Centaurea calcitrapa. Oregon Department of Agriculture, Salem.

Funk, D. J., P. Nosil, and W. J. Etges. 2006. Ecological divergence exhibits consistently positive associations with reproductive isolation across disparate taxa. Proceedings of the National Academy of Sciences of the USA 103:3209-3213.

Garcia-Jacas, N., T. Uysal, K. Romashchenko, V. N. Suárez-Santiago, K. Ertugrul, and A. Susanna. 2006. Centaurea revisited: a molecular survey of the Jacea group. Annals of Botany 98:741-753.

Gerlach, J. D. 1997. The introduction, dynamics of geographic range expansion, and ecosystem effects of yellow starthistle (Centaurea 
solstitialis). Proceedings of the California Weed Science Society 49: 136-141.

$\rightarrow$ Gerlach, J. D., and K. J. Rice. 2003. Testing life history correlates o $\rightarrow$ invasiveness using congeneric plant species. Ecological Applications 13:167-179.

$\rightarrow$ Heiser, C. B., and T. W. Whitaker. 1948. Chromosome number, polyploidy and growth habit in California weeds. American Journal of Botany 35:179-186.

Hendry, A. P. 2004. Selection against migrants contributes to the rapid evolution of ecologically dependent reproductive isolation Evolutionary Ecology 6:1219-1236.

$\rightarrow$ Hendry, A. P., P. Nosil, and L. H. Rieseberg. 2007. The speed of ecological speciation. Functional Ecology 21:455-464.

$\rightarrow$ Hierro, J. L., Ö. Eren, L. Khetsuriani, A. Diaconu, K. Török, D. Montesinos, K. Andonian, et al. 2009. Germination responses of an invasive species in native and non-native ranges. Oikos 118: 529-538.

$\rightarrow$ Hulme, P. E. 2007. Biological invasions in Europe: drivers, pressures, states, impacts and responses. Issues in Environmental Science and Technology 25:56-80.

$\rightarrow$ James, J. K., and R. J. Abbott. 2005. Recent, allopatric, homoploid hybrid speciation: the origin of Senecio squalidus (Asteraceae) in the British Isles from a hybrid zone on Mount Etna, Sicily. Evolution 59:2533-2547.

$\rightarrow$ Lowry, D. B., J. L. Modliszewski, K. M. Wright, C. A. Wu, and J. H. Willis. 2008. The strength and genetic basis of reproductive iso lating barriers in flowering plants. Philosophical Transactions of the Royal Society B: Biological Sciences 363:3009-3021.

$\rightarrow$ MacNair, M. R., and P. Christie. 1983. Reproductive isolation as a pleiotropic effect of copper tolerance in Mimulus guttatus? Heredity 50:295-302.

Maddox, D. M., A. Mayfield, and N. H. Poritz. 1985. Distribution of yellow starthistle (Centaurea solstitialis) and Russian knapweed (Centaurea repens). Weed Science 33:315-327.

$\rightarrow$ Maron, J. L., M. Vilà, R. Bommarco, S. Elmendorf, and P. Beardsley. 2004. Rapid evolution of an invasive plant. Ecological Monographs 74:261-280.

Mayr, E. 1942. Systematics and the origin of species. Columbia University Press, New York.

$\rightarrow$ Muth, N. Z., and M. Pigliucci. 2006. Traits of invasives reconsidered: phenotypic comparisons of introduced invasive and introducec noninvasive plant species within two closely related clades. American Journal of Botany 93:188-196.

Norusis, M. J. 2002. SPSS 11.0: guide to data analysis. Prentice Hall, Upper Saddle River, NJ.

$\rightarrow$ Pimentel, D., R. Zuniga, and D. Morrison. 2005. Update on the environmental and economic costs associated with alien-invasive species in the United States. Ecological Economics 52:273-288.

$\rightarrow$ Pitcairn, M. J., J. A. Young, C. D. Clements, and J. O. E. Balciunas. 2002. Purple starthistle (Centaurea calcitrapa) seed germination. Weed Technology 16:452-456.

$\rightarrow$ Powell, A. M., D. W. Kyhos, and P. H. Raven. 1974. Chromosome numbers in Compositae. X. American Journal of Botany 61:909913.

Ramsey, J., H. D. Bradshaw Jr., and D. W. Schemske. 2003. Components of reproductive isolation between the monkeyflowers $\mathrm{Mi}$ mulus lewisii and M. cardinalis (Phrymaceae). Evolution 57:15201534.

R Development Core Team. 2010. R: a language and environment for statistical computing. R Foundation for Statistical Computing, Vienna.

Rice, W. R., and E. E. Hostert. 1993. Laboratory experiments on speciation: what have we learned in 40 years? Evolution 47:16371653.

Ridenour, W. M., J. M. Vivanco, Y. Feng, J. I. Horiuchi, and R. M. Callaway. 2008. No evidence for trade-offs: Centaurea plants from America are better competitors and defenders. Ecological Monographs 78:369-386.

$\rightarrow$ Rieseberg, L. H., and B. K. Blackman. 2010. Speciation genes in plants. Annals of Botany 106:439-455.

Robbins, W. W. 1940. Alien plants growing without cultivation in California. Bulletin 637. California Agricultural Experiment Station, Berkeley.

Schemske, D. W. 2010. Adaptation and the origin of species. American Naturalist 176(suppl.):S4-S25.

Schluter, D. 2000. The ecology of adaptive radiation. Oxford University Press, Oxford.

. 2001. Ecology and the origin of species. Trends in Ecology \& Evolution 16:372-380.

$\rightarrow$ Sun, M., and K. Ritland. 1998. Mating system of yellow starthistle (Centaurea solstitialis), a successful colonizer in North America. Heredity 80:225-232.

$\rightarrow$ Vellend, M., L. J. Harmon, J. L. Lockwood, M. M. Mayfield, A. R. Hughes, J. P. Wares, and D. F. Sax. 2007. Effects of exotic species on evolutionary diversification. Trends in Ecology \& Evolution 22: 481-488.

Venables, W. N., and B. D. Ripley. 2002. Modern applied statistics with S. 4th ed. Springer, New York.

$\rightarrow$ Whitney, K. D., and Gabler, C. A. 2008. Rapid evolution in introduced species, "invasive traits" and recipient communities: challenges for predicting invasive potential. Diversity and Distributions 14:569580 .

Widmer, T. L., F. Guermache, M. Y. Dolgovskaia, and S. Y. Reznik. 2007. Enhanced growth and seed properties in introduced vs. native populations of yellow starthistle (Centaurea solstitialis). Weed Science 55:465-473.

$\rightarrow$ Wolf, J. B. W., J. Lindell, and N. Backström. 2010. Speciation genetics: current status and evolving approaches. Philosophical Transactions of the Royal Society B: Biological Sciences 365:1717-1733.

Zuur, A. F., E. N. Ieno, N. Walker, A. A. Saveliev, and G. M. Smith. 2009. Mixed effects models and extensions in ecology with R. Springer, New York.

Natural History Editor: Craig W. Benkman 